\title{
Mapping Proteome Changes in Microsatellite Stable, Recurrent Colon Cancer Reveals a Significant Immune System Signature
}

\author{
MAGNUS BERLE ${ }^{1,2,3}$, KJERSTI E. HESTETUN ${ }^{4,5}$, HEIDRUN VETHE ${ }^{1}$, SIMONA CHERA ${ }^{4,6}$, \\ JOAO A. PAULO ${ }^{7}$, OLAV DAHL ${ }^{4,5}$ and METTE PERNILLE MYKLEBUST ${ }^{5}$ \\ ${ }^{1}$ Department of Clinical Medicine, University of Bergen, Bergen, Norway; \\ ${ }^{2}$ Department of Surgery, Haukeland University Hospital, Bergen, Norway; \\ ${ }^{3}$ Department of Surgery, Haraldsplass Deaconess Hospital, Bergen, Norway; \\ ${ }^{4}$ Department of Clinical Science, University of Bergen, Bergen, Norway; \\ ${ }^{5}$ Department of Oncology and Medical Physics, Haukeland University Hospital, Bergen, Norway; \\ ${ }^{6}$ Department of Medicine, Division of Endocrinology, Diabetes, \\ Nutrition and Patient Education, University Hospital of Geneva, Geneva, Switzerland; \\ ${ }^{7}$ Department of Cell Biology, Harvard Medical School, Boston, MA, U.S.A.
}

\begin{abstract}
Background/Aim: Better stratification of the risk of relapse will help select the right patients for adjuvant treatment and improve targeted therapies for patients with colon cancer. Materials and Methods: To understand why a subset of tumors relapse, we compared the proteome of two groups of patients with colon cancer with similar stage, stratified based on the presence or absence of recurrence. Results: Using tumor biopsies from the primary operation, we identified dissimilarity between recurrent and nonrecurrent mismatch satellite stable colon cancer and found that signaling related to immune activation and inflammation was associated with relapse. Conclusion: Immune modulation may have an effect on mismatch satellite stable colon cancer. At present, immune therapy is offered primarily to microsatellite instable colon cancer. Hopefully, immune therapy in mismatch satellite stable colon cancer beyond PD-1 and PD-L1 inhibitors can be implemented.
\end{abstract}

Colorectal cancer is the third most common type of cancer in men and second in women, accounting for 10 and $9.2 \%$, respectively, of total cancer cases worldwide (1). Colon cancer typically develops from a benign precursor adenoma that is visible on the mucosal surface of the colon. Primary

This article is freely accessible online.

Correspondence to: Magnus Berle, University of Bergen, Department of Clinical Medicine, Pb 7804, 5020 Bergen, Norway. Tel: +47 98042039, e-mail: magnus.berle@uib.no

Key Words: Colon cancer, microsatellite stable, recurrence, proteomics, immune system. treatment following early detection is surgery, with postoperative adjuvant therapy for selected groups based on the histopathological findings in the operation specimen - in principle when lymph node involvement is detected. Colon cancer is staged according to the Union Internationale Contre le Cancer (UICC) TNM system, stratifying the local growth of the tumour, the spread to lymph nodes and the distant metastases (2). The TNM stage correlates well with the prognosis and the recurrence rate and is used to group the disease into stages as a measure of the severity of cancer.

There are at least three distinct pathways in colorectal cancer pathogenesis: the chromosomal instability (CIN), microsatellite instability (MSI), and $\mathrm{CpG}$ island methylator phenotype (CIMP) pathways (3). The molecular mechanisms underlying cancer development are multifactorial, however initial disease mechanisms in colorectal cancer suggest activation of the canonical Wnt signalling pathway, through mutations in the $A P C$ (4) and $\beta$-catenin (5) genes, followed by accumulation of somatic mutations in KRAS (6) and $P I 3 K$ (7), and inactivation of TGF- $\beta$ (8) as well as the p53 pathway (8). The microsatellite instable high (MSI-H) cancers have a defect in mismatch repair (MMR) proteins, leaving spontaneous mutations un-repaired during DNA replication, thus causing frame-shift mutations or silenced genes (9). MSI-H cancers are in general hypermutated, expressing several neoantigens causing a strong immune response (10). This effect is linked to the response to immune therapy by PD-1 and PD-L1 inhibitors (11-14).

The role of immunity and immune activation in colorectal cancer has been thoroughly reviewed by several authors (10, 15-19). A subgroup of microsatellite stable (MSS) tumors has high immune activation, but at present a clear set of criteria for the tumors responding to of immune therapy has not been 
defined (12). Identifying candidates for immune therapy in MSS may help improve the outcome of subgroups of CRC.

In recent years, the Consensus Molecular Subtypes (CMS) can predict prognosis (20-22). A challenge with this classification is that it is technically demanding and time consuming, and not all patients can be clearly allocated to the four groups. Tools such as ColoType (23) help stratify CMS based on RNA signature with prognostic value. However, CMS stratification is still complex partly due to cell heterogeneity (24) and the predictive utility is still limited. Proteomics and subsequent pathway analyses may play a role in understanding and clarifying the mechanisms underlying the risk of recurrent disease.

Vasaikar et al. (25) has recently published a proteogenomic characterization of colon cancer, analysing 110 patients with a broad set of omics methodologies. A major finding was that proteomics identified an association between decreased CD8 T-cell infiltration and increased glycolysis in MSI-H tumors, suggesting glycolysis as a potential target to overcome the resistance of MSI-H tumors to immune checkpoint blockade. For the non-hypermutated cancers, somatic mutations are most frequent in APC, TP53, SMAD4, PIK3CA, KRAS, TCF7L2, SOX9, ARID1A and FAM123B (26). A better characterization of the molecular mechanisms underlying the differences, in particular between stages TNM2 and TNM3, is warranted. Identifying specific protein signatures for recurrence risk of these two stages are of clinical interest. There are potential markers for stratifying recurrence risk, but none are validated and implemented to current clinical use (27).

The aim of the present study was to identify proteins associated with relapse, which can help in selecting patients who need adjuvant therapy after surgery. This study is a feasibility study based on a limited material and the objective was thus to assess the value of large-scale proteomic analyses of perioperative biopsies from colon cancer patients. The main current clinical problem is that we need to treat many patients unnecessarily to rescue those with high risk of new tumor activity. In order to pinpoint these proteins, we have identified differentially expressed proteins that may contribute to progression into relapse, by comparing relapse versus non-relapse samples. We also describe the proteomic differences between TNM2 and TNM3 as these patient-groups receive different treatment based on staging at initial diagnosis.

\section{Materials and Methods}

Patients. The patients included in the present study are from a cohort of 265 patients with localized colon cancer that were included in a prospective study from January 2007 to December 2011 (28), with perioperative biopsies collected by the operating surgeon. In this cohort, 78 patients had pMMR-tumour material stored in RNA-Later. The patients included were selected based on matching similar TNM and remission status groups on tumor site, recurrence status, age and gender to reduce bias. Distant metastases were excluded by chest and abdomen CT imaging. A complete mesocolic resection (CME) with high vascular tie was performed. No patient received neoadjuvant chemotherapy or radiation. Patients under 70 years received adjuvant chemotherapy according to the Nordic FLOX regimen, whereas patients between 70 and 75 years were treated by the Nordic FLv regimen if there was nodal spread $(29,30)$. The study was conducted according to the guidelines of the Declaration of Helsinki and approved by the Regional Ethics Committee West (REK Vest 15666), the Norwegian Medicines Control Authority and the Data Inspectorate and thus comply with national regulations.

Surgical resection was performed at Haraldsplass Deaconess Hospital, Bergen, Norway. All patients included were diagnosed with MSS colon adenocarcinomas. The patients were followed-up for minimum five years. The regular check-up included clinical examination, CEA blood test and computed tomography (CT) of the chest and abdomen every sixth month for three years, then yearly to the fifth year after surgery. Colonoscopy was done every three years. We had access to the full records of the patients, both during treatment and follow-up for five years, including relapse status. The material included patients with TNM stages I-III of colon cancer.

Processing of biopsy material: Tissue lysis and protein digestion. Per-operative biopsies from tumour tissue and control tissue were obtained from 25 patients with sufficient fresh-frozen material available. Biopsies ( $n=50,25$ tumour and 25 normal colon tissue samples) were cut and homogenized in $0.5 \mathrm{ml}$ Dulbecco's phosphate buffered saline (DPBS) and TissueLyzer. Samples were sonicated three times for $30 \mathrm{~s}$ at $30 \%$ power, followed by centrifugation at $14,000 \times g$ for $3 \mathrm{~min}$. The supernatant was transferred to a new tube, and the protein concentration was measured using the Bradford assay. From each sample $20 \mu \mathrm{g}$ total protein were stored at $-80^{\circ} \mathrm{C}$ before further processing. Five samples of $20 \mu \mathrm{g}$ were pooled (Table I) to make $100 \mu \mathrm{g}$ samples. The same was done for the respective normal tissue samples and ten pooled samples of $100 \mu \mathrm{g}$ protein were processed for proteomics.

The entire amount of protein $(100 \mu \mathrm{g})$ in each sample was reduced, alkylated and digested into peptides with trypsin. The peptide samples were TMT-labelled (10-plex) (Thermo Fisher, San Jose, CA, USA) and fractionated as described in (31).

Tandem mass tag (TMT) 10-plex labelling. TMT reagents were resuspended in acetonitrile (ACN). Desalted peptides were resuspended in $100 \mu \mathrm{l}$ of $200 \mathrm{mM}$ HEPES pH 8.5, $30 \mu \mathrm{l}$ of ACN, and $10 \mu \mathrm{l}$ of the TMT reagents were added to the respective peptide samples, gently vortexed, and incubated for $1.5 \mathrm{~h}$ at room temperature (RT). To prevent unwanted labelling, the reaction was quenched by adding $10 \mu \mathrm{l}$ of $5 \%$ hydroxylamine and incubated for $15 \mathrm{~min}$ at RT. Equal amounts of the TMT-labelled samples were combined and concentrated to near dryness, followed by desalting via $\mathrm{C} 18$ solid phase extraction.

Off-line basic pH reversed phase fractionation. The combined labelled peptide samples were pre-fractionated by basic $\mathrm{pH}$ reversed phase HPLC as described previously (32), using an Agilent (P/N 770995-902) 300Extend-C18, $5 \mu \mathrm{m}, 250 \mathrm{~mm} \times 4.6 \mathrm{~mm}$ id column, connected to an Agilent Technology off-line LC-system (Santa 
Berle et al: Proteomics Reveals Immune Signature in Recurrent MSS Colon Cancers

Table I. Patient characteristics, primary tumor site, primary tumor histology, primary tumor grade, lymph nodes and positive lymph nodes.

\begin{tabular}{|c|c|c|c|c|c|}
\hline Group & TNM1 & TNM2 r- & TNM2 r+ & TNM3 r- & TNM3 r+ \\
\hline \multicolumn{6}{|l|}{ Age } \\
\hline Average & 77.6 & 67.4 & 65.4 & 65.4 & 69 \\
\hline Median & 79 & 67 & 67 & 65 & 71 \\
\hline $\operatorname{Max}$ & 85 & 85 & 76 & 82 & 93 \\
\hline Min & 66 & 56 & 51 & 50 & 42 \\
\hline Standard deviation & 7.1 & 11.0 & 10.5 & 13.7 & 19.8 \\
\hline Gender & 4 Male, 1 Female & 2 Male, 3 Female & 3 Male, 2 Female & 3 Male, 2 Female & 3 Male, 2 Female \\
\hline \multicolumn{6}{|l|}{ Primary tumor site } \\
\hline Coecum/colon ascendens & 2 & 1 & 1 & 3 & 1 \\
\hline Colon transversum & 1 & 1 & 1 & 0 & 2 \\
\hline Colon descendens & 0 & 0 & 0 & 0 & 0 \\
\hline Colon sigmoideum & 2 & 2 & 1 & 1 & 2 \\
\hline Rectosigmoideum & 0 & 1 & 2 & 1 & 0 \\
\hline \multicolumn{6}{|l|}{ Primary tumor histology } \\
\hline Adenocarcinoma & $100 \%$ & $100 \%$ & $100 \%$ & $100 \%$ & $100 \%$ \\
\hline Microsatellite stable & $100 \%$ & $100 \%$ & $100 \%$ & $100 \%$ & $100 \%$ \\
\hline \multicolumn{6}{|l|}{ Primary tumor grade } \\
\hline Well differentiated & 2 & 1 & 1 & 0 & 0 \\
\hline Moderate differentiated & 3 & 4 & 3 & 5 & 4 \\
\hline Poorly differentiated & 0 & 0 & 1 & 0 & 1 \\
\hline \multicolumn{6}{|c|}{ Total number of lymph nodes } \\
\hline Average & 11.6 & 26.8 & 15.2 & 14.6 & 18 \\
\hline $\mathrm{SD}$ & 1.9 & 20.3 & 4.5 & 3.4 & 4.3 \\
\hline \multicolumn{6}{|c|}{ Average number of positive lymph nodes } \\
\hline Average & 0 & 0 & 0 & 3 & 5 \\
\hline $\mathrm{SD}$ & & & & 1.6 & 3.7 \\
\hline
\end{tabular}

TNM: Tumor node metastasis; SD: standard deviation.

Clara, CA, USA). Solvent A was $5 \% \mathrm{ACN}, 10 \mathrm{mM} \mathrm{NH}_{4} \mathrm{HCO}_{3} \mathrm{pH}$ 8 , and solvent $\mathrm{B}$ was $90 \% \mathrm{ACN}, \mathrm{NH}_{4} \mathrm{HCO}_{3} \mathrm{pH}$ 8. The samples were re-suspended in $500 \mu \mathrm{l}$ solvent $\mathrm{A}$ and loaded onto the column. Column flow was set to $0.8 \mathrm{ml} / \mathrm{min}$ and the gradient length was 70 min, as follows: from $0-35 \mathrm{~min}$ solvent $50 \% \mathrm{~A} / 50 \% \mathrm{~B}$, and from $35-50$ min $100 \% \mathrm{~B}$, and from $50-70$ min $100 \% \mathrm{~A}$. The labelled peptides were fractionated into 96 fractions, and further combined into a total of 12 fractions. Each fraction was acidified with $1 \%$ formic acid, concentrated by vacuum centrifugation to near dryness, and desalted by StageTip. Each fraction was dissolved in 5\% ACN/ $5 \%$ formic acid for LC-MS/MS analysis.

LC-MS3 analysis. From each of the 12 fractions, $\sim 5 \mathrm{~g}$ was dissolved in $1 \%$ aqueous formic acid (FA) prior to LC-MS/MS analysis on an Orbitrap Fusion mass spectrometer (Thermo Fisher Scientific) coupled to a Proxeon EASY-nLC 1000 liquid chromatography (LC) pump (Thermo Fisher Scientific). Peptides were fractionated on a $75-\mu \mathrm{m}$ inner diameter microcapillary column packed with $\sim 0.5 \mathrm{~cm}$ of Magic C4 resin [5 $\mu \mathrm{m}, 100 \AA$, Michrom Bioresources (Auburn, CA, USA)] followed by $\sim 35 \mathrm{~cm}$ of GP-18 resin $(1.8 \mu \mathrm{m}, 200 \AA$, Sepax, Newark, DE, USA). For each analysis, we loaded $\sim 1 \mu \mathrm{g}$ onto the column.

Peptides were separated using a $3 \mathrm{hr}$ gradient of 6 to $26 \%$ ACN in $0.125 \% \mathrm{FA}$ at a flow rate of $\sim 350 \mathrm{nl} / \mathrm{min}$. Each analysis used the multi-notch MS3-based TMT method (33) on an Orbitrap Fusion mass spectrometer, which has been shown to reduce ion interference compared to MS2 quantification (32). The scan sequence began with an MS1 spectrum (Orbitrap analysis; resolution 120,000; mass range 400-1400 m/z; automatic gain control (AGC) target $2 \times 10^{5}$; maximum injection time $100 \mathrm{~ms}$ ). Precursors for MS2/MS3 analysis were selected using a TopSpeed of $2 \mathrm{~s}$. MS2 analysis consisted of collision-induced dissociation (quadrupole ion trap analysis; AGC $4 \times 10^{3}$; normalized collision energy (NCE) 35 ; maximum injection time $150 \mathrm{~ms}$ ). Following acquisition of each MS2 spectrum, we collected an MS3 spectrum using our recently described method (33) in which multiple MS2 fragment ions were captured in the MS3 precursor population using isolation waveforms with multiple frequency notches. MS3 precursors were fragmented by high-energy collision-induced dissociation (HCD) and analysed using the

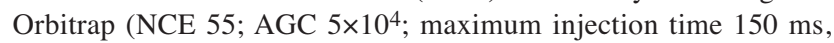
resolution was 60,000 at $400 \mathrm{Th}$ ).

Data analysis. Mass spectra were processed using a Sequest-based in-house software pipeline (34), and spectra were converted to mzXML using a modified version of ReAdW.exe. Database searching included all entries from the human UniProt database (March 11, 2014). This database was concatenated with one composed of all protein sequences in the reversed order. Searches were performed using a $50 \mathrm{ppm}$ precursor ion tolerance for total protein level analysis. The product ion tolerance was set to 0.9 Da. These wide mass tolerance windows were chosen to maximize sensitivity in conjunction with Sequest searches and linear discriminant analysis $(34,35)$. TMT tags on lysine residues and peptide $\mathrm{N}$ termini $(+229,163 \mathrm{Da})$ and carbamidomethylation of 
A

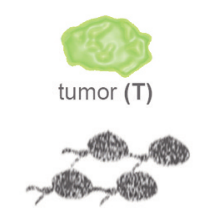

lymph nodes (N)

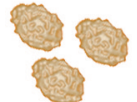

metastases (M)
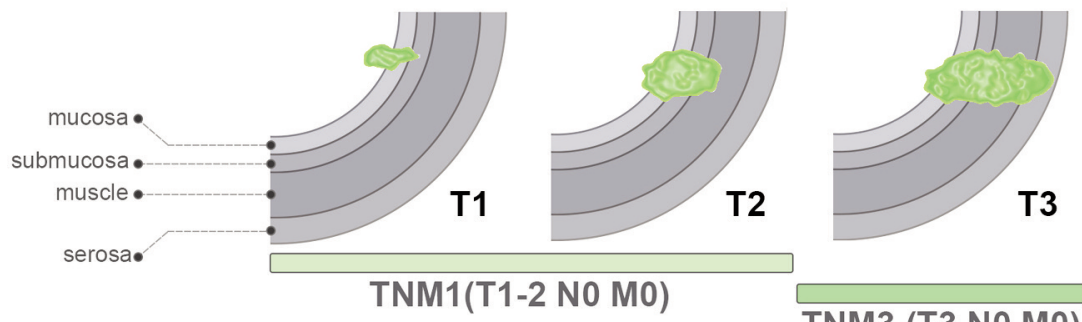

TNM3 (T3 NO M0)

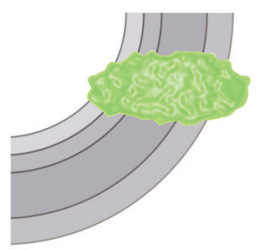

B

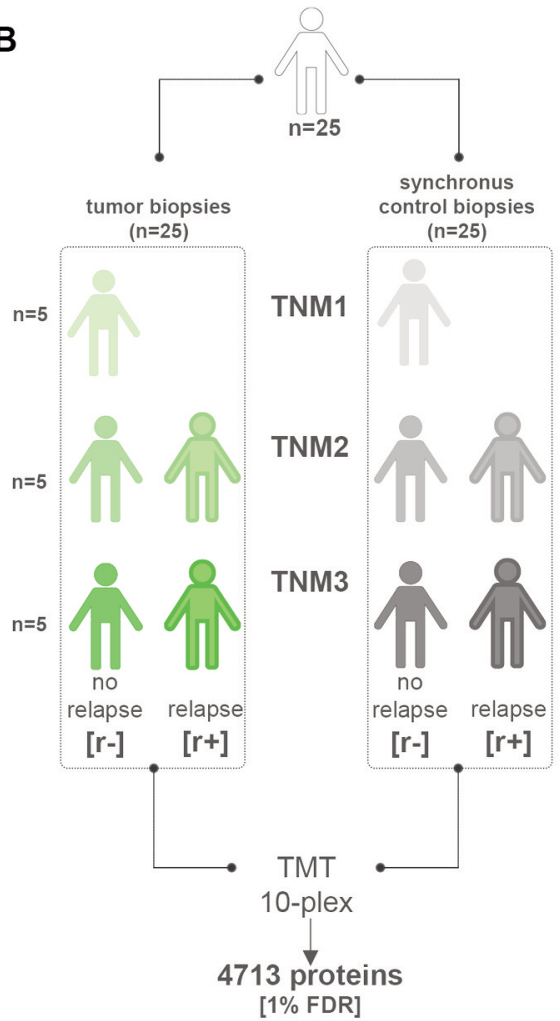

$\mathbf{E}$

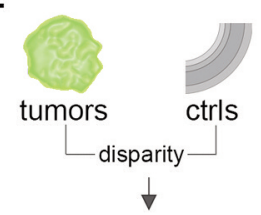

[cluster 1] $\cup$ [cluster15]

$$
\downarrow
$$

2919 proteins

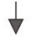

pathway analysis

[IPA]
C

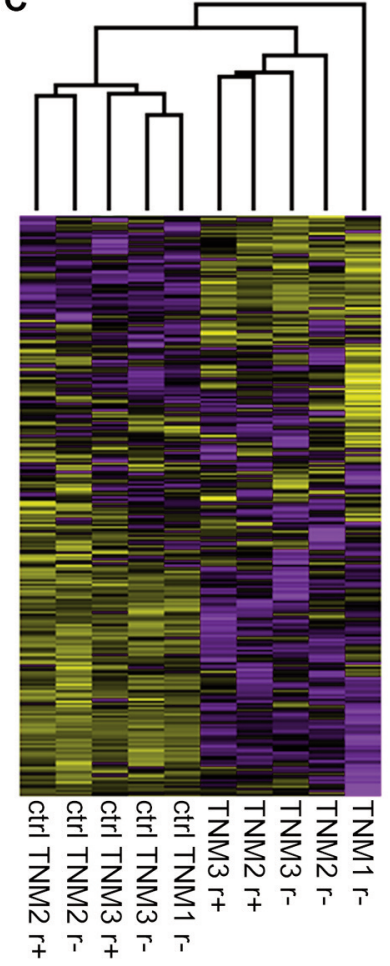

D Cluster 1

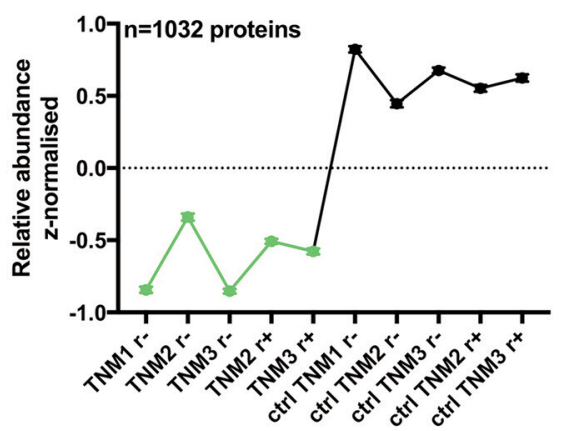

Cluster 15

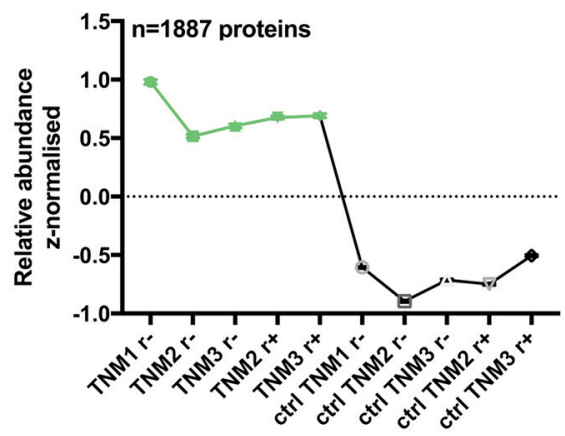

$\mathbf{F}$

TOP 10 CANONICAL PATHWAYS

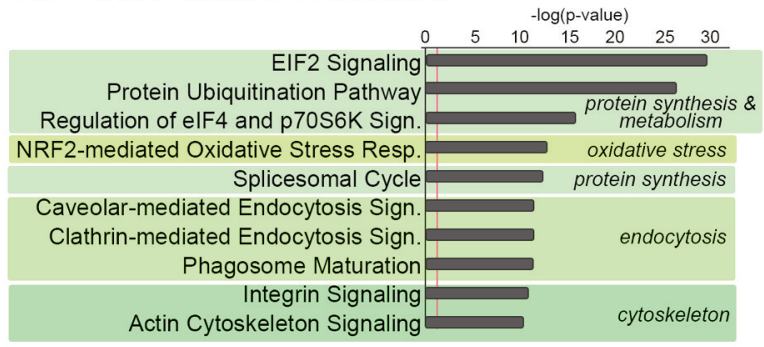

G

TOP PREDICTED UPSTREAM REGULATORS

\begin{tabular}{ll}
\hline name & $p$-value of overlap \\
MYC & $1.83 E-66$ \\
HNF4A & $8.77 E-57$ \\
TP53 & $1.17 E-48$ \\
MYCN & $7.45 E-40$ \\
CST5 & $4.80 E-38$
\end{tabular}


H [low abundance in tumors]

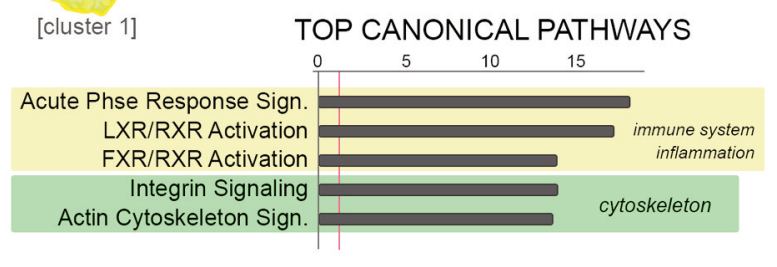

I

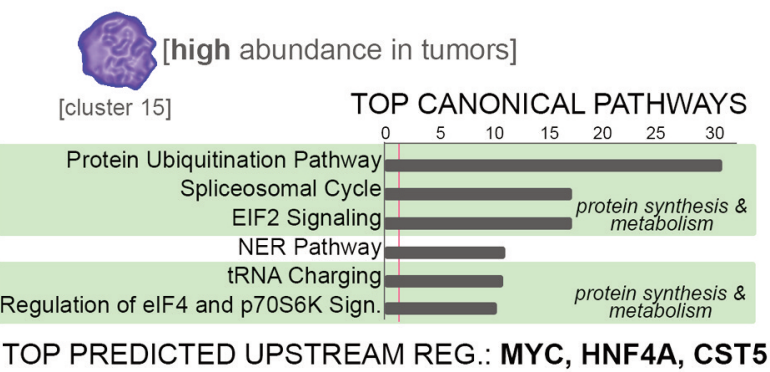

Figure 1. Cluster analysis of the cancer samples. (A) Cartoon depicting tumour development and the stages selected for this study according to the TNM system. (B) Experimental design depicting the cohorts employed and workflow. (C) Hierarchical analysis of the proteome landscape in the 10 different samples ( $n=5$ /sample/TNM stage). (D) Graphs depicting the centroid of Cluster \#1 and Cluster \#15 (light green - Cancer samples, black - control samples) and the total number of proteins belonging to each cluster. (E) Scheme depicting the proteome analysis workflow. (F) Top 10 Canonical Pathways characterising the analysed proteome landscape, as determined by Ingenuity Pathway Analysis (IPA) software. (G) Top Predicted Upstream Regulators for the analysed proteome landscape, as inferred by IPA. (H) Top Canonical Pathways and Top Predicted Upstream Regulators characterising the group of proteins with low abundance in the tumour samples (Cluster \#1), as determined by pathway analysis (IPA). (I) Top Canonical Pathways and Predicted Upstream Regulators characterising the group of proteins with high abundance in the tumour samples (Cluster \#15), as determined by pathway analysis (IPA).

cysteine residues $(+57,021 \mathrm{Da})$ were set as static modifications, while oxidation of methionine residues $(+15,995 \mathrm{Da})$ was set as a variable modification.

Peptide-spectrum matches (PSMs) were adjusted to a $1 \%$ false discovery rate (FDR) $(36,37)$. PSM filtering was performed using a linear discriminant analysis, as described previously (34), while considering the following parameters: XCorr, $\Delta \mathrm{Cn}$, missed cleavages, peptide length, charge state, and precursor mass accuracy. For TMTbased reporter ion quantitation, we extracted the summed signal-tonoise $(\mathrm{S} / \mathrm{N})$ ratio for each TMT channel and found the closest matching centroid to the expected mass of the TMT reporter ion.

The search space for each reporter ion was limited to a range of $0.003 \mathrm{Th}$ to prevent overlap between the isobaric reporter ions. For protein-level comparisons, PSMs were identified, quantified, and collapsed to a $1 \%$ peptide false discovery rate (FDR) and then collapsed further to a final protein-level FDR of $1 \%$. Moreover, protein assembly was guided by principles of parsimony to produce the smallest set of proteins necessary to account for all observed peptides.

Proteins were quantified by summing reporter ion counts across all matching PSMs using in-house software, as described previously (34). PSMs with poor quality, MS3 spectra with more than eight TMT reporter ion channels missing, MS3 spectra with TMT reporter summed signal-to-noise ratio that was less than 100, or no MS3 spectra were excluded from quantitation (38). Protein quantitation values were exported for further analysis in Microsoft Excel (Redmond WA, USA) or SAS JMP (Cary, NC, USA). Each reporter ion channel was summed across all quantified proteins and normalized assuming equal protein loading of all 10 samples.

The pathway analyses were generated using QIAGEN's Ingenuity Pathway Analysis (IPA ${ }^{\circledR}$, Redwood City, CA, USA). Briefly, the analyses were performed with the following settings: Expression Value Type (Exp Log Ratio), Reference set (Ingenuity Knowledge Base + Endogenous chemicals), Relationships to consider (Direct and Indirect Relationships), Interaction networks (35 molecules/network; 25 networks/analysis), Data Source (all),
Confidence (Experimentally Observed), Species (Human, Mouse, Rat), Tissue \& Cell Lines (all), Mutations (all).

The clustering analyses were performed in Perseus version 1.5.6.0 (39). Roughly, data were imported as $\log 2$-transformed data. Z-score normalization was performed based on rows. Hierarchical clustering was performed with settings Euclidian distance, averaged linkage with preprocessing k-means both in rows and columns tree. We defined 15 row clusters, exported protein list and analysed on basis of group means with SEM. In selection for proteins with a differential expression, we used a threshold of 1.5 in fold change.

The mass spectrometry proteomics data have been deposited to the ProteomeXchange Consortium via the PRIDE $(40,41)$ partner repository with the dataset identifier PXD026630.

\section{Results}

Per-operative biopsies were resected from tumour tissue and control tissue from 25 patients diagnosed with microsatellite stable colon adenocarcinomas (Patient characteristics are shown in Table I). From a total of 50 samples (tumour and normal tissue samples), tissues from five patients were grouped according to TNM staging (Figure 1A) as well as recurrence status into five pools of tumor tissue (TNM1, TNM2R+, TNM2R-, TNM3R+, TNM3R-) and normal colon tissues resected from the same patients (Figure 1B). The samples were pooled independent of gender, age and location of the tumour at initial diagnosis (right-side or left-side colon cancer). As the focus of this study was evaluating the differences in the proteome of tumors from colon cancer patients with recurrence versus patients without recurrence, we restricted our attention to MSS colon adenocarcinomas diagnosed with TNM stage 1,2 and 3, including TNM2 and TNM3 with and without recurrence. 
A

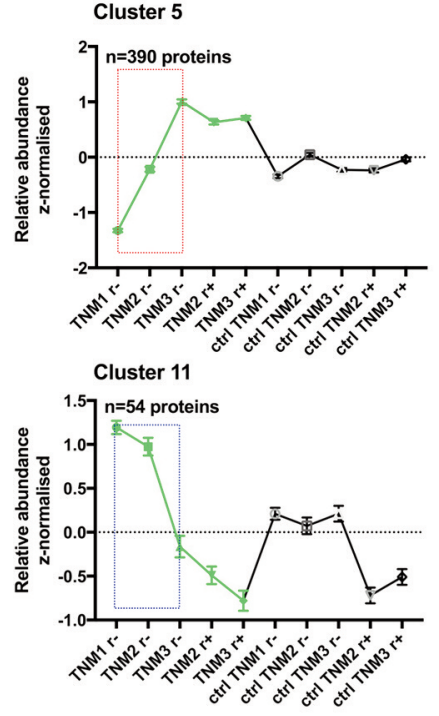

B

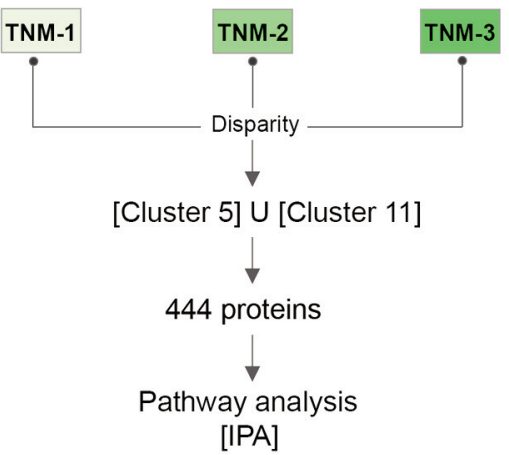

C

TOP CANONICAL PATHWAYS

endocytosis

immunesystem 10

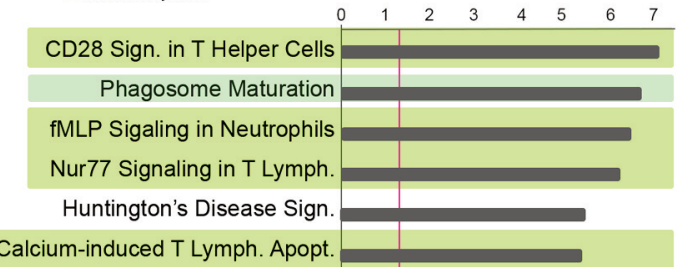

TOP PREDICTED UPSTREAM REGULATORS

Name $\quad p$-value of overlap

HNF4A 2.87E-13

MAPT $1.11 \mathrm{E}-06$

PTP4A3 1.56E-06

PSEN1 1.08E-05

TGFB1 3.72E-05

NFE2L2 $1.43 \mathrm{E}-05$
D

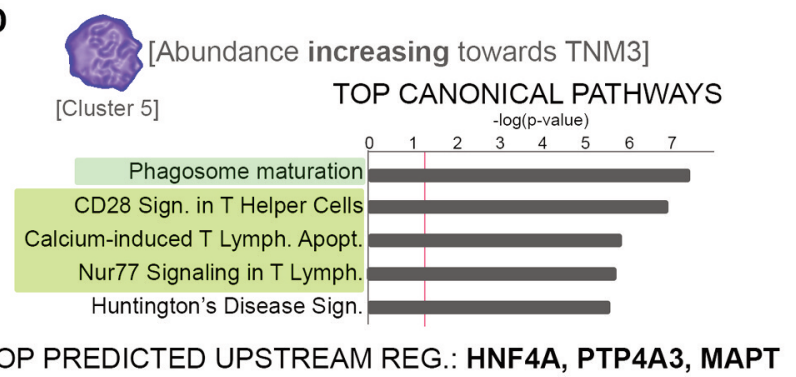

E

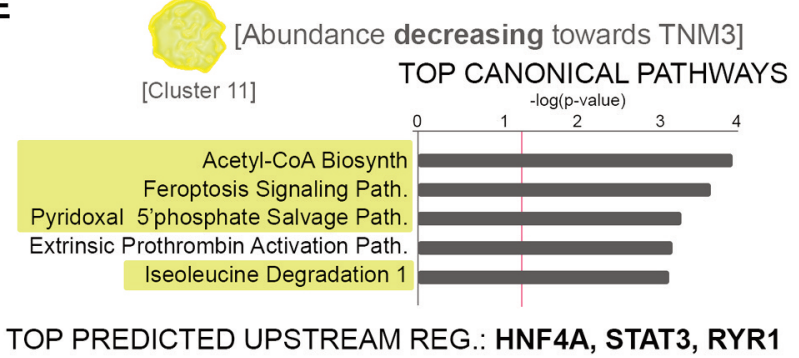

Figure 2. Pathway analysis of the proteins displaying a gradual variation in abundance according to TNM stage. (A) Graphs depicting the centroid of Cluster \#5 and Cluster \#11 (light green - Cancer samples, black - control samples, red rectangle highlights the increase (upper panel) of protein abundance according to TNM stage, blue rectangle highlights the decrease (lower panel) of protein abundance according to TNM stage) and the total number of proteins belonging to each cluster. (B) Scheme depicting the proteome analysis workflow. (C) Top Canonical Pathways and Top Predicted Upstream Regulators characterising the analysed proteome landscape, as determined by Ingenuity Pathway Analysis (IPA) software. (D) Top Canonical Pathways and Predicted Upstream Regulators characterising the group of proteins with gradually increased abundance towards TNM3 (Cluster \#5), as determined by pathway analysis (IPA). (E) Top Canonical Pathways and Top Predicted Upstream Regulators characterising the group of proteins with gradually decreased abundance towards TNM3 (Cluster \#11), as determined by pathway analysis (IPA).

Our proteomics analysis allowed for confident (1\% FDR) identification of 4,805 protein quantified across all ten samples with at least one unique peptide sequence. A further elimination of known contaminants left 4,713 proteins (Figure 1B).

Relapse samples were distinguishable by specific protein signatures indicating risk of recurrent colon cancer. To describe the proteome changes that influence the progression to relapse, we clustered the tumor tissue samples based on similarity. Hierarchical clustering across all proteins identified clearly discriminates between the tumor and control samples (Figure 1C), while TNM2 and TNM3 subgroups clustered separately from TNM1. Of interest, the recurring tumor groups (TNM2R+ and TNMR3+) clustered closest. These results suggest that tumor samples and healthy tissue are characterised by considerably different proteome fingerprints and that the tumors of patients with later relapse are defined by specific proteome signatures distinct from the primary tumor of patients without later relapse (Figure 1C).

Cluster analysis revealed proteome signatures associated with protein synthesis, cellular remodelling and stress. As an initial analysis we clustered all 4,713 quantified proteins based on their abundance profiles between patient groups to obtain an unbiased view of the proteome changes occurring during colon cancer progression. Interestingly, our results showed that 2919 proteins (61\%) separated cancer and 
A

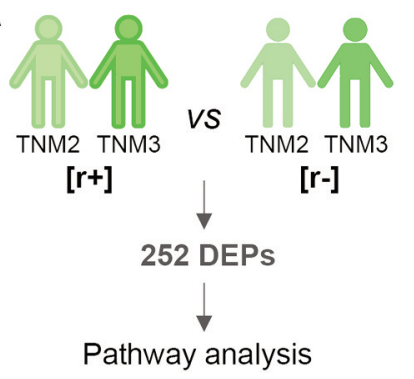

[IPA]
B

TOP 10 CANONICAL PATHWAYS WITH PREDICTED REGULATION

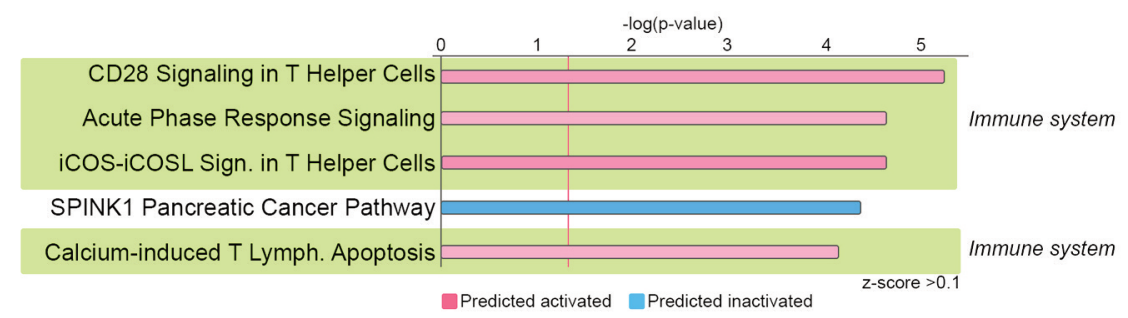

C

TOP PREDICTED ACTIVATED UPSTREAM
\begin{tabular}{lcc}
\multicolumn{3}{c}{ REGULATORS } \\
\hline Name & Activation z-score & $p$-value of overlap \\
IFNG & 3.313 & $6.05 \mathrm{E}-05$ \\
interferon $\alpha$ & 3.072 & $5.08 \mathrm{E}-04$ \\
IFNA2 & 2.909 & $3.04 \mathrm{E}-06$ \\
IFNL1 & 2.769 & $4.27 \mathrm{E}-06$ \\
IL27 & 2.609 & $1.08 \mathrm{E}-03$
\end{tabular}

D

TOP PREDICTED INHIBITED UPSTREAM
\begin{tabular}{ccc}
\multicolumn{3}{c}{ REGULATORS } \\
\hline Name & Activation z-score & p-value of overlap \\
MAPK1 & -3.148 & $1.12 \mathrm{E}-03$ \\
AGT & -2.757 & $2.70 \mathrm{E}-04$ \\
RC3H1 & -2.646 & $1.10 \mathrm{E}-06$ \\
SP110 & -2.449 & $4.38 \mathrm{E}-03$ \\
IRGM & -2.236 & $2.22 \mathrm{E}-04$
\end{tabular}

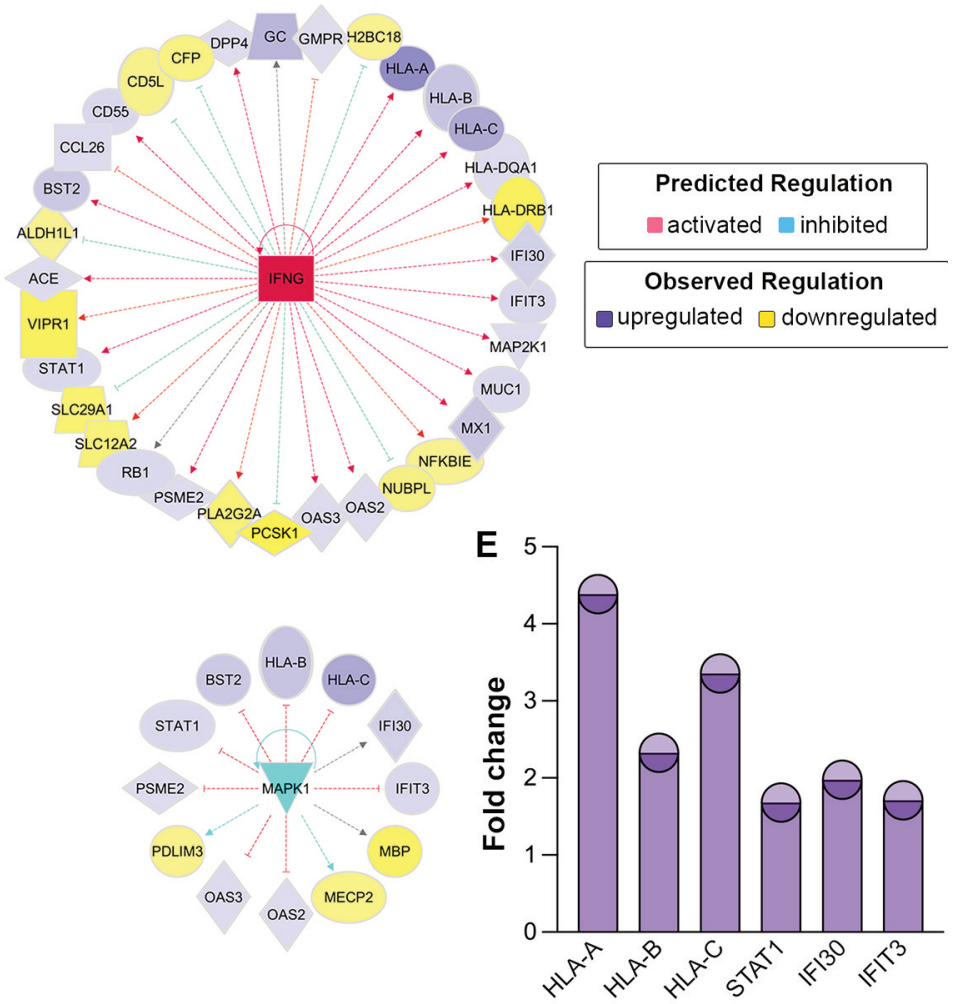

Figure 3. Pathway analysis of the differentially expressed proteins (DEPS) between overall TNMR+ and TNMR-. (A) Scheme depicting the proteome analysis workflow. (B) Top Canonical Pathways with predicted regulation characterizing the TNMR+vs. TNMR-DEPs landscape, as determined by Ingenuity Pathway Analysis (IPA) software (z-score >0.1). (C) Top 5 Predicted Activated Upstream Regulators and IFNG targeted proteins observed regulated in the DEP set analyzed. (D) Top 5 Predicted Inhibited Upstream Regulators and MAPK1 targeted proteins observed regulated in the DEP set analyzed. (E) Graph of relevant DEPs observed dysregulated in TNMR+.

control samples collected from the same patients. Among these, two distinct clusters emerged (Cluster \#1 and Cluster \#15) separating TNM stage 1-3 as compared to control samples, regardless of the relapse status (Figure 1D).

Pathway analysis of the combined clusters (i.e., all the 2919 proteins separating cancer and control samples, Figure 1E) predict that the 10 most important canonical pathways involver are related to translation, antioxidant activity, endocytosis and cytoskeleton remodelling (Figure 1F). Pathways related with protein synthesis represented the dominant signature, suggesting that the relapsed tumours present an altered protein metabolism (Figure 1F). Importantly, the top 5 upstream regulators responsible for the observed proteome landscape included transcription regulators tightly linked with malignant transformation such as MYC, HNF4A, TP53 and MYCN (Figure 1G).

Subsequently, we addressed each cluster separately to distinguish which of the tumor signatures identified above are defined by increased or decreased abundance of proteins in tumor tissue relative to normal tissue. Pathway analysis 
A

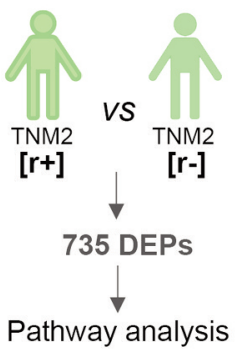

[IPA]
B

TOP CANONICAL PATHWAYS WITH PREDICTED REGULATION

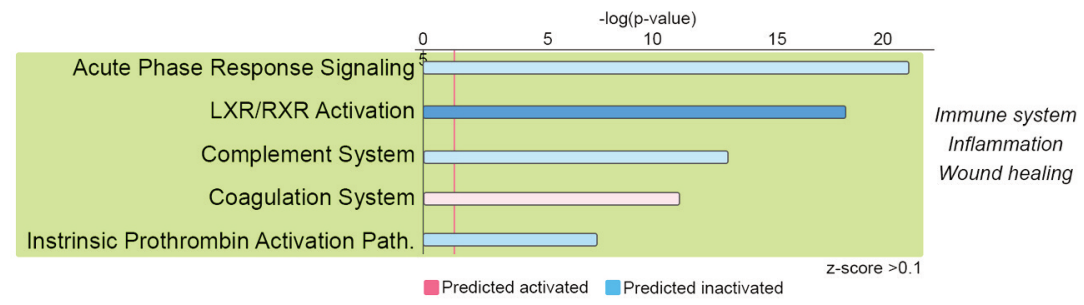

C

TOP PREDICTED ACTIVATED UPSTREAM
\begin{tabular}{lcc}
\multicolumn{3}{c}{ REGULATORS } \\
\hline Name & Activation z-score & p-value of overlap \\
AHR & 3.277 & $2.60 \mathrm{E}-04$ \\
MYC & 2.894 & $5.20 \mathrm{E}-09$ \\
INHA & 2.828 & $1.38 \mathrm{E}-02$ \\
IFNG & 2.801 & $1.16 \mathrm{E}-10$ \\
CD38 & 2.782 & $7.44 \mathrm{E}-06$ \\
KRAS & 2.774 & $3.52 \mathrm{E}-09$
\end{tabular}

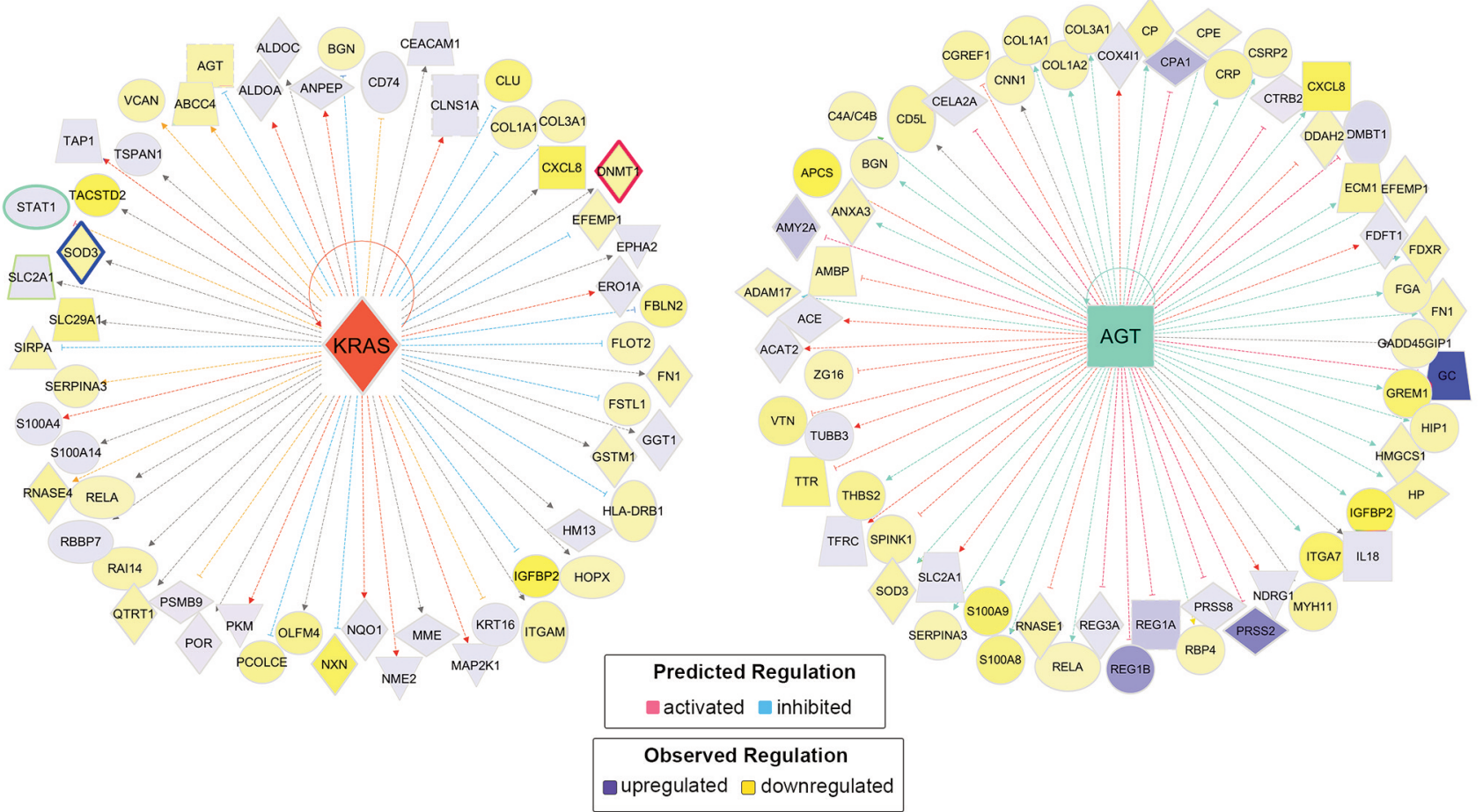

D TOP PREDICTED INHIBITED UPSTREAM REGULATORS

\begin{tabular}{lcc}
\hline Name & Activation z-score & $p$-value of overlap \\
AGT & -3.442 & $9.38 \mathrm{E}-11$ \\
IL1A & -3.430 & $8.88 \mathrm{E}-03$ \\
CCR2 & -3.308 & $8.62 \mathrm{E}-09$ \\
PRDM1 & -3.082 & $1.19 \mathrm{E}-04$ \\
MTPN & -2.985 & $7.82 \mathrm{E}-04$
\end{tabular}

Figure 4. Continued revealed that cytoskeleton remodelling fingerprint was characterised by proteins with low abundance in the tumour (Figure 1H). Moreover, this proteome landscape (cluster 1) was compatible with the predicted action of upstream regulators with known cancer connection, such as HRAS (top
1), TGFB1 (top 2) and TP53 (top 3). Of importance, TGFB1I1 and its downstream effector SMAD4 were found in cluster 1 , presenting a very low abundance in the cancer samples.

In contrast, proteins with high abundance in tumor (Cluster 15, Figure 1I) strongly defined the proteome 

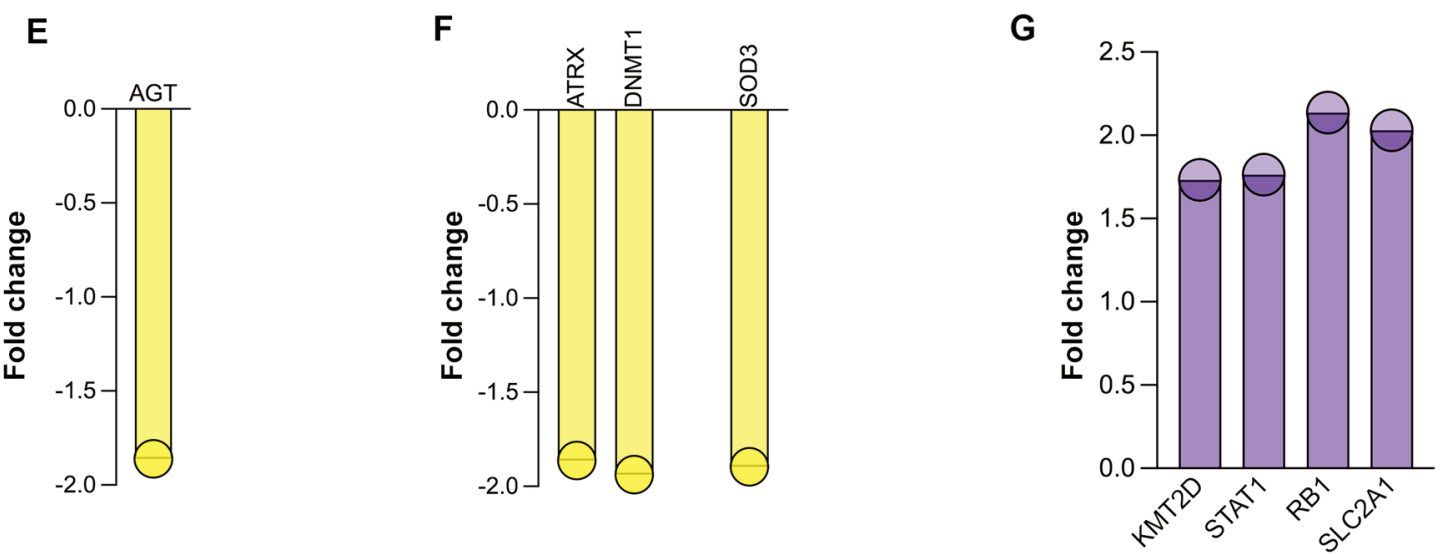

Figure 4. Pathway analysis of the differentially expressed proteins (DEPs) between TNM2R+ and TNM2R-. (A) Scheme depicting the proteome analysis workflow. (B) Top Canonical Pathways with predicted regulation characterizing the TNM2R+vs. TNM2R-DEPs landscape, as determined by Ingenuity Pathway Analysis (IPA) software (z-score $>0.1)$. (C) Top 5 Predicted Activated Upstream Regulators and KRAS targeted proteins observed regulated in the DEP set analysed (coloured borders define DEPs discussed in text). (D) Top 5 Predicted Inhibited Upstream Regulators and AGT targeted proteins observed regulated in the DEP set analysed. (E) Graph depicting AGT observed down-regulated. (F) Graph depicting relevant DEPs observed down-regulated in TNM2R+. $(G)$ Graph depicting relevant DEPs observed up-regulated in TNM $2 R+$.

fingerprint related to protein synthesis. Based on this subset, the analysis predicted the involvement of another set of key cancer regulators $M Y C$ (top 1), HNF4A (top 2) and CST5 (top 3). $M Y C B P$ belonged to cluster 15 and displayed a high abundance in the cancer samples.

These data indicate that cancer and control samples are mainly distinguished by differences in protein synthesis and remodelling regardless of the malignant relapse potential, and these processes are likely controlled by critical cell fate regulators, such as $M Y C, T G F B$ or TP53.

Of interest, a lower percentage of transcription regulators were present in the cluster encompassing proteins with lower abundance in the cancer samples (cluster \#1, 4.26\%) than in the cluster of the proteins with higher abundance (cluster 15, $9.48 \%$ ), suggesting that, at least in this case, most processes driving tumour development are controlled via increases in protein abundance.

At individual level, epigenetic modifiers such as the deacetylase MIDEAS (mitotic deacetylase associated SANT domain protein, ELMSAN1), the methyltransferases METTL7A, METTL7B, and METTL14, and the DNA methylation reader MECP2 presented a lower abundance in the tumour tissues. Of interest, receptors with a key role in growth regulation such as $E G F R$ and critical players of cancer development such as K-RAS, SMAD4, GSK3B, $M A P K 1, M A P K 3, A P P L 1$, and $R A F 1$ were also characterized by low abundance in the cancer samples.

In contrast, critical transcription regulators such as $R B 1$, STAT1, STAT6, MTA2 and YAP1 as well as the growth receptor like INSR displayed higher abundance in the tumour tissue. Moreover, kinases previously demonstrated to drive cancer development such as MTOR, SRC, ROCK2, RAC2, $P I K 3 R 4, P I K 3 C D, P I K 3 R 1$ exhibited the same regulation.

Proteins displaying TNM-stage dependent changes in abundance define immune system-related signatures. To map the signatures defining the progression of the disease, we identified two clusters (Cluster \#5 and \#11) where the abundance of the grouped proteins changes with increasing TNM stage (Figure 2A). As before, we used IPA and performed pathway analysis on the 444 proteins exhibiting the above-described regulatory pattern (Figure 2B). The analysis identified a strong immune system signature, with signaling involved in immune system regulation in the top canonical pathways (Figure 2C). Based on the observed proteome landscape, HNF4A, MAPT, PTP4A3, PSEN1, TGFB1 and NFE2L2 were identified as top predicted upstream regulators.

Interestingly, the identified immune signature was defined exclusively by proteins showing increased abundance with TNM stages (cluster 5, Figure 2D, greens). At individual level, this group contained important epigenetic modifiers such as the lysine methyltransferase $K M T 2 D$ and the histone deacetylases $H D A C 1$ and $H D A C 2$, that all displayed increasingly elevated levels with disease progression.

In contrast, the proteins with opposite regulation controlled small molecule metabolism (cluster 11, Figure 2E, yellow). Moreover, this group contained only two distinct transcription regulators, further confirming its low involvement in the regulatory process.

The analysis of the common relapse proteome landscape revealed a strong immune system signature. To map the 
A

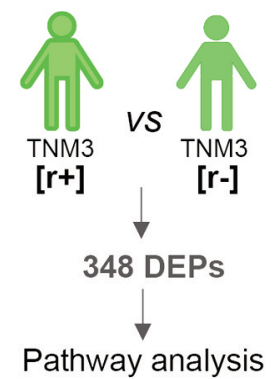

[IPA]

\section{B}

TOP CANONICAL PATHWAYS WITH PREDICTED REGULATION

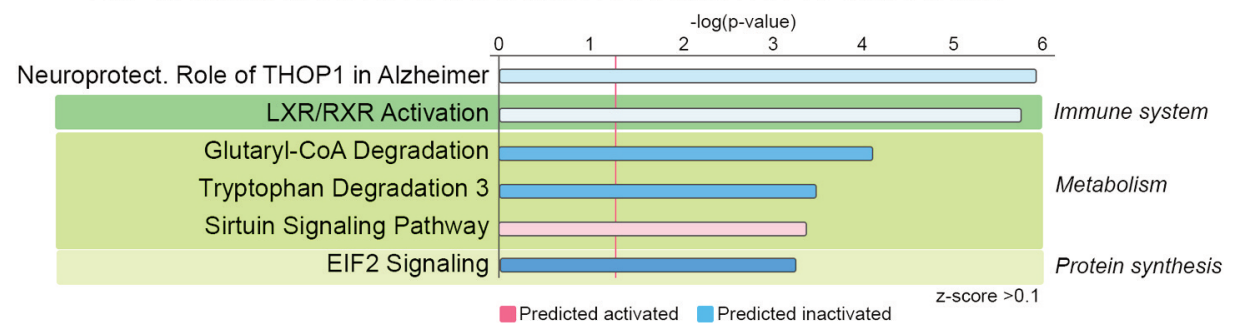

\section{C}

TOP PREDICTED ACTIVATED UPSTREAM
\begin{tabular}{lcc}
\multicolumn{3}{c}{ REGULATORS } \\
\hline Name & Activation z-score & $p$-value of overlap \\
RICTOR & 3.207 & $1.01 \mathrm{E}-04$ \\
IL1A & 2.932 & $2.85 \mathrm{E}-05$ \\
IRF7 & 2.916 & $1.23 \mathrm{E}-03$ \\
CEBPB & 2.877 & $6.38 \mathrm{E}-06$ \\
LARP1 & 2.828 & $3.60 \mathrm{E}-05$ \\
EGF & 2.793 & $7.66 \mathrm{E}-05$ \\
IL17A & 2.792 & $6.85 \mathrm{E}-05$ \\
IL6 & 2.740 & $1.10 \mathrm{E}-10$
\end{tabular}

D

TOP PREDICTED INHIBITED UPSTREAM

\begin{tabular}{lcc}
\multicolumn{3}{c}{ REGULATORS } \\
\hline Name & Activation z-score & $p$-value of overlap \\
MLXIPL & -3.162 & $1.75 \mathrm{E}-05$ \\
HOXA10 & -2.772 & $6.70 \mathrm{E}-03$ \\
IL10RA & -2.688 & $2.97 \mathrm{E}-04$ \\
RC3H1 & -2.646 & $1.26 \mathrm{E}-05$ \\
MYCN & -2.555 & $4.44 \mathrm{E}-04$
\end{tabular}

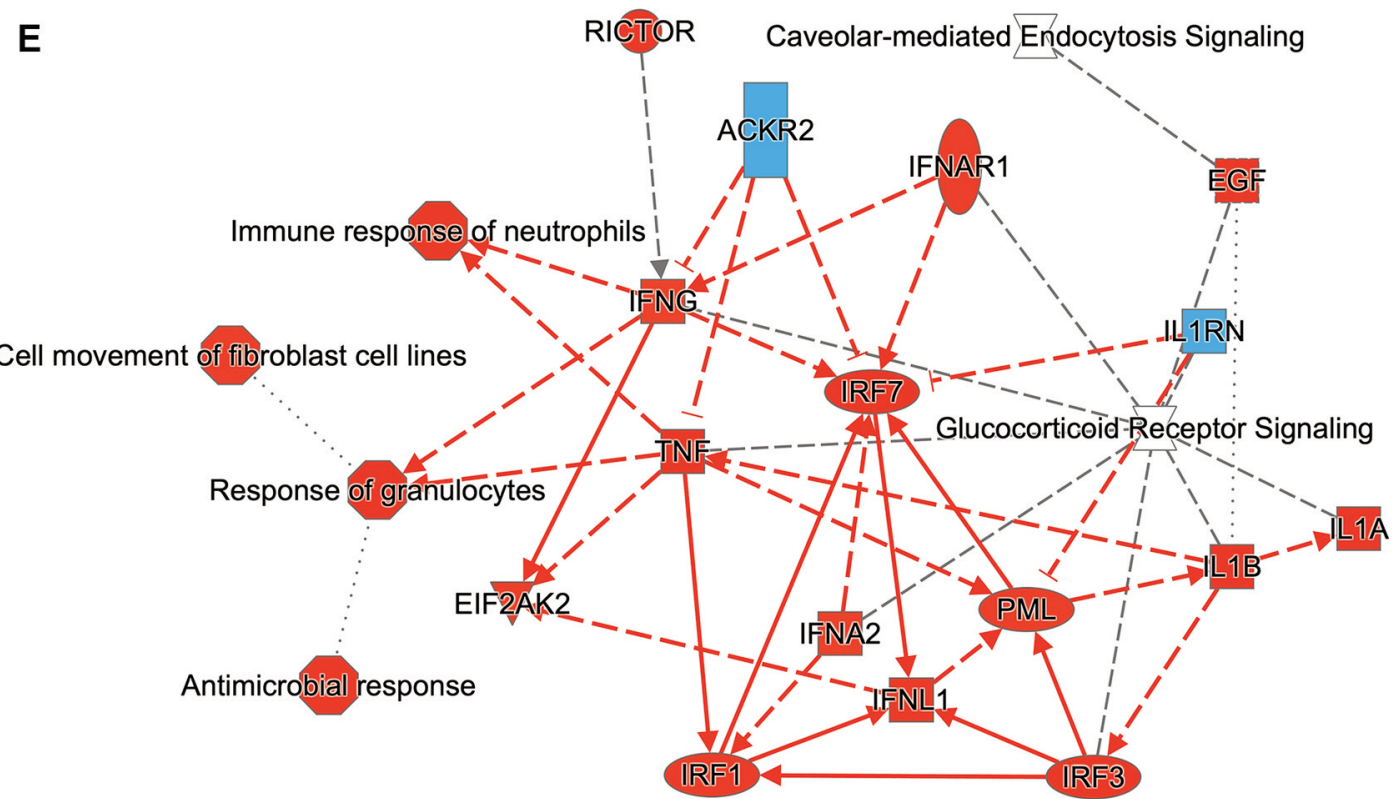

Figure 5. Continued 

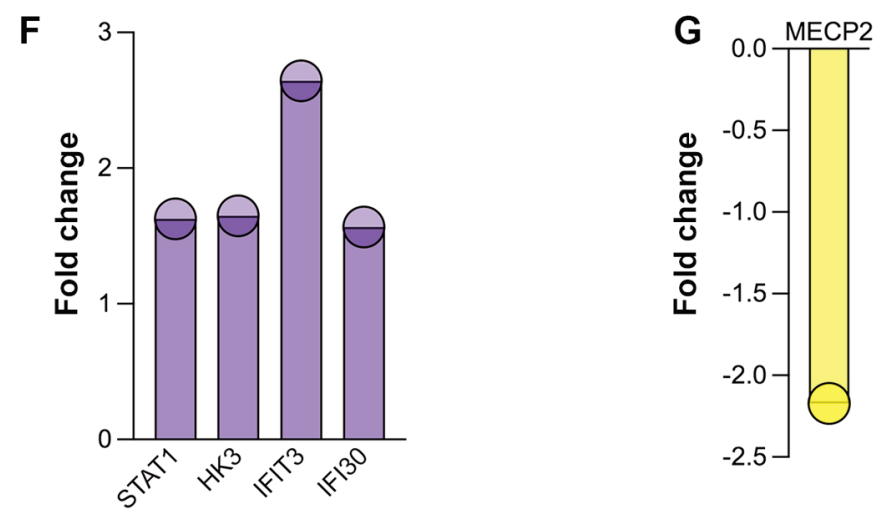

Figure 5. Pathway analysis of the differentially expressed proteins (DEPs) between TNM3R+ and TNM3R-. (A) Scheme depicting the proteome analysis workflow. (B) Top Canonical Pathways with predicted regulation characterizing the TNM3R+vs. TNM3R-DEPs landscape, as determined by Ingenuity Pathway Analysis (IPA) software (z-score >0.1). (C) Top 5 Predicted Activated Upstream Regulators and IL1A targeted proteins observed regulated in the DEP set analyzed (colored borders define DEPs discussed in text). (D) Top 5 Predicted Inhibited Upstream Regulators and ILIORA targeted proteins observed regulated in the DEP set analysed. (E) IPA generated graphical summary of the analyzed proteome landscape. (F) Graph depicting relevant DEPs observed up-regulated in TNM3R+. (G) Graph MECP2 observed down-regulation in TNM3R+.

molecular mechanisms behind disease relapse we compared tumour tissue from the patient groups that suffered from recurrent disease (TNM2R+ and TNM3R+) with those from the group of patients with the same initial diagnosis but recurrence-free (TNM2R- and TNM3R-). We found 252 differentially expressed proteins $(\mathrm{FC}>1.5)$ between $\mathrm{R}+$ (TNM2 and TNM3) and R- (TNM2 and TNM3). These 252 proteins define a common relapse signature and were further analysed using IPA (Figure 3A).

The pathway analysis revealed signalling related to immune system and inflammation in the top canonical pathways (Figure 3B). Further confirming this result, based on the observed proteome landscape, interferon gamma $(I F N G)$ as well as other critical immune system regulators (IFNA2, IFNL1 and IL27) were predicted as top activated upstream regulators based on the observed proteome landscape (Figure 3C). As top inhibited upstream regulators the program predicted the $M A P K$ (Figure 3D). The inferred activity of both $I F N G$ and $M A P K$ was based on the observed up-regulation of proteins like the transcriptional effector of the interferon pathway STAT1, the major histocompatibility complexes HLA-A, HLA-B and HLA-C, and interferoninduced proteins IFI30, IFIT, amongst others (Figure 3E).

TNM2 relapse signature further corroborated the immune system engagement. To further investigate the proteome adaptations underlying the progression from non-relapsing to relapsing within the group of patients with TNM2 colon adenocarcinomas, the proteome of TNM2R+ versus TNM2R- were compared. We found 735 differentially expressed proteins $(\mathrm{FC}>1.5)$ between $\mathrm{TNM} 2 \mathrm{R}+$ and TNM2R- (Figure 4A). Pathway analysis reconfirmed the presence in the top canonical pathways of signalling related to immune system, inflammation and wound healing (Figure 4B). Moreover, in the top upstream regulators the program inferred amongst others the immunity regulator $A H R$ and $I F N G$ as well as the proto-oncogenes $M Y C$ and KRAS (Figure 4C). Activation of KRAS, known for its involvement in colorectal cancer, was predicted based on 56 distinct proteins observed dysregulated in our dataset, amongst which the DNA methylase DNMT1, the superoxide dismutase SOD3, the glucose transporter GLUT1 (SLC2Al) and the transcription factor STAT1.

Interestingly, angiotensin $(A G T)$ was predicted as the lead inhibited upstream regulator, while the inflammatory cytokine IL1A, the chemokine receptor CCR2 and the key regulator of plasma cell differentiation, B-cell development, and antibody production PRDM1 followed (Figure 4D). Of note, AGT was also observed down-regulated in the analysed DEP group (Figure 4E).

At individual levels, when comparing TNM2R+versus TNM2R-, the chromatin remodelers ATRX and DNMT1 and the antioxidant enzyme SOD3 were found down-regulated (Figure 4F), while the epigenetic modifier $K M T 2 D$, the transcription regulators $S T A T 1$ and $R B 1$ as well as the glucose transporter $S L C 2 A I$ were observed up-regulated (Figure 4G).

TNM3 relapse signature revealed a link between metabolism and the immune system. To describe the TNM3 relapse signature, we focused on the 348 differentially expressed proteins $(\mathrm{FC}>1.5)$ between TNM3R+ and TNM3R- (Figure 5A). Pathway analysis indicated mainly signalling involved in growth metabolism and immune system (Figure 5B). RICTOR, 
a nutrient and growth factor integrative hub, was the top predicted activated upstream regulator defining the observed proteome landscape, followed by two regulators involved in inflammation and immune system signalling (Figure 5C). Similarly, the top predicted inactivated upstream regulator was $M L X I P L$, a glucose-controlled regulator of lipid metabolism (Figure 5D). Moreover, the graphical pathway integration of the proteome landscape characterising the TNM3R+/TNM3Rcomparison, displayed an intricate interconnection between growth metabolism and immune system (Figure 5E).

At individual level, we observed the up-regulation of STAT1 transcription factor, similar to the above analysis of the TNMR2+ samples (Figure 5F). Moreover, the glucose metabolism enzyme hexokinase 3 (HK3) and the interferoninduced proteins IFI30 and IFIT followed the same regulation, while the methylation maintaining factor MECP2 was found down-regulated.

Overall, our results suggest a clear involvement of inflammation and immune system regulation in relapse occurrence in colon cancer. Moreover, the pathway analysis suggests a link between the immune system and growth metabolism in this context.

\section{Discussion}

Proteomics profiling in colorectal cancer is a powerful tool for describing the molecular characteristics underlying TNM staging. It can be a useful tool in discovering protein signatures between relapsing and non-relapsing tumours. High-throughput proteomics have the ability to capture changes in thousands of proteins simultaneously and are therefore a useful platform for biomarker discoveries. In this study, we used TMT 10-plex quantitative proteomics approach for profiling the proteome of resected tumour tissue and autologous normal colon tissue. We created pools consisting of five patients in each group, selecting only for TNM-stage and recurrence status. There are several studies stating that there is a difference in the tumor biology dependent on the location of the primary tumor $(20,42,43)$. The objective of the present study was to assess the differences in the proteome of colon cancer on basis of TNM stage and histology. The patients included in this study were classified by clinical pathological data. For a future study, we would advocate primary CMS-typing, as well as CIN/CIMP-classification to heighten the quality of the patient material as well as increase the subclassification of tumors included. This is not currently a part of ESMO clinical practice guidelines (44).

There is a need for good studies matching well selected clinical patient material with adequate methodology. A particular finding in this study was the strong association in/between MSS and immune activation, currently not part of standard treatment. This finding is well discussed previously by Mlecnic et al. (10). Our relapse signatures predicted genes such as JAK1, SERPINB3, RICTOR, ACKR2, $S T A T, T N F$ and $K R A S$ to be involved, but call for validation in larger patient cohorts. Still, we demonstrated the methodological ability to identify changes that can discern the ability to metastasise at an early timepoint (operations specimen biopsy) in an unbiased fashion.

The finding of differential abundance in IFN between TNM2+ and TNM 3+versus TNM2- and TNM3- groups correlates with the experimental model by Shankaran et al. (45), suggesting IFN activation in primary tumors play a role in predicting future recurrent disease.

The finding that immune activation promotes tumor activation seems rather contra intuitive. There is currently a lack of clinical models of how tumors adapt to the immune system, but it is well known that immune activation has a large anti-tumor activity in early stages. More advanced tumors seem to adapt to the immune system to promote growth and metastatic colonization. Gonzales et al. (46) presents a thorough review on the roles of the immune system in cancer. In CRC, there are several studies on immune evasion, also in presumed "cold" MSS CRC, in particular those by Tauriello et al. (47), Wang et al. (48), Xiao et al. (49) and Klement et al. (50). This feasibility study lacks the power to elucidate the mechanisms involved concerning immune alteration in tumor microenvironment, but the findings might represent detection of tumor microenvironment alterations in recurrent CRC.

We interpret our results on the basis that the differences in proteome are rather large than small, causing $61 \%$ of proteins to separate cancer and control in cluster analyses with $\mathrm{FC}<1.5$. This change in proteome illustrated in Figure 1 represents a phenotypic change in cancer tissue, primarily on cancer-related and an associated alteration in the household proteins. Reducing complexity in a dataset to increase the signal/noise ratio is a challenge, our cluster strategy is an unsupervised way to filter the proteins where statistical significance represents biological significance. This study is underpowered for a full characterization of proteome change in recurrent versus nonrecurrent colon cancer but presents insight in the feasibility of such a study. There are few large studies with data on clinical follow-up. In the transition to clinical application, there is a current unmet need for studies of recurrent disease.

\section{Conclusion}

In this feasibility study that included MSS colon cancer only, signalling related to immune activation and inflammation were the top canonical pathways associated with relapse. Immunotherapy is known to induce durable responses in both non-metastatic and metastatic MSI-H CRC, but only a minority of MSS patients respond to the current available treatment. Still, as most CRC patients have MSS tumours, identifying subgroups of MSS patients that may respond to immunotherapy 
will generate new treatment options for a significant number of patients. Our findings in this feasibility study show the ability of proteomics to detect changes in immune activation. If these results are validated in larger experiments, this implies that immune therapy may become an important avenue for selected MSS colon cancer patients with risk of relapse.

\section{Conflicts of Interest}

K.H has been on an advisory board for Daiichi Sankyo. The other Authors declare no conflict of interest in relation to this study. The funders had no role in the design of the study; in the collection, analyses, or interpretation of data; in the writing of the manuscript, or in the decision to publish the results.

\section{Authors' Contributions}

Conceptualization: M.B., K.H., H.V., O.D. and M.M.; investigation: M.B., K.H., H.V., S.C., J.P. and M.M.; data curation: J.P.; writingoriginal draft preparation: M.B. and O.D.; writing-review and editing: M.B., K.H., H.V., S.C., O.D., and M.M..; visualization: H.V. and S.C..; project administration: M.B. and M.M.; funding acquisition: O.D. All Authors have read and agreed to the published version of the manuscript.

\section{Acknowledgements}

This research was funded by Helse Vest and Trond Mohn Stiftelse. S.C. was supported by funds from the Research Council of Norway (NFR 251041) and Novo Nordic Foundation (NNF15OC0015054 and NNF21OC0067325).

\section{References}

1 Ferlay J, Soerjomataram I, Dikshit R, Eser S, Mathers C, Rebelo M, Parkin DM, Forman D and Bray F: Cancer incidence and mortality worldwide: sources, methods and major patterns in GLOBOCAN 2012. Int J Cancer 136(5): E359-E386, 2015. PMID: 25220842. DOI: 10.1002/ijc.29210

2 Sobin L, Gospodarowicz M and Wittekind C: Tnm classification of malignant tumours ( 7 th edn). International Union Against Cancer, Wiley-Blackwell Oxford, 2009.

3 Pino MS and Chung DC: The chromosomal instability pathway in colon cancer. Gastroenterology 138(6): 2059-2072, 2010. PMID: 20420946. DOI: 10.1053/j.gastro.2009.12.065

4 Powell SM, Zilz N, Beazer-Barclay Y, Bryan TM, Hamilton SR, Thibodeau SN, Vogelstein B and Kinzler KW: APC mutations occur early during colorectal tumorigenesis. Nature 359(6392): 235-237, 1992. PMID: 1528264. DOI: 10.1038/359235a0

5 Morin PJ, Sparks AB, Korinek V, Barker N, Clevers H, Vogelstein B and Kinzler KW: Activation of beta-catenin-Tcf signaling in colon cancer by mutations in beta-catenin or APC. Science 275(5307): 1787-1790, 1997. PMID: 9065402. DOI: 10.1126/science. 275.5307 .1787

6 Bos JL, Fearon ER, Hamilton SR, Verlaan-de Vries M, van Boom JH, van der Eb AJ and Vogelstein B: Prevalence of ras gene mutations in human colorectal cancers. Nature 327(6120): 293-297, 1987. PMID: 3587348. DOI: 10.1038/327293a0
7 Bardelli A, Parsons DW, Silliman N, Ptak J, Szabo S, Saha S, Markowitz S, Willson JK, Parmigiani G, Kinzler KW, Vogelstein $\mathrm{B}$ and Velculescu VE: Mutational analysis of the tyrosine kinome in colorectal cancers. Science 300(5621): 949, 2003. PMID: 12738854 . DOI: 10.1126/science.1082596

8 Markowitz S, Wang J, Myeroff L, Parsons R, Sun L, Lutterbaugh J, Fan RS, Zborowska E, Kinzler KW and Vogelstein B: Inactivation of the type II TGF-beta receptor in colon cancer cells with microsatellite instability. Science 268(5215): 1336-1338, 1995. PMID: 7761852. DOI: 10.1126/science. 7761852

9 Boland CR and Goel A: Microsatellite instability in colorectal cancer. Gastroenterology 138(6): 2073-2087.e3, 2010. PMID: 20420947. DOI: 10.1053/j.gastro.2009.12.064

10 Mlecnik B, Bindea G, Angell HK, Maby P, Angelova M, Tougeron D, Church SE, Lafontaine L, Fischer M, Fredriksen T, Sasso M, Bilocq AM, Kirilovsky A, Obenauf AC, Hamieh M, Berger A, Bruneval P, Tuech JJ, Sabourin JC, Le Pessot F, Mauillon J, Rafii A, Laurent-Puig P, Speicher MR, Trajanoski Z, Michel P, Sesboüe R, Frebourg T, Pagès F, Valge-Archer V, Latouche JB and Galon J: Integrative analyses of colorectal cancer show immunoscore is a stronger predictor of patient survival than microsatellite instability. Immunity 44(3): 698-711, 2016. PMID: 26982367. DOI: 10.1016/j.immuni.2016.02.025

11 Le DT, Uram JN, Wang H, Bartlett BR, Kemberling H, Eyring AD, Skora AD, Luber BS, Azad NS, Laheru D, Biedrzycki B, Donehower RC, Zaheer A, Fisher GA, Crocenzi TS, Lee JJ, Duffy SM, Goldberg RM, de la Chapelle A, Koshiji M, Bhaijee F, Huebner T, Hruban RH, Wood LD, Cuka N, Pardoll DM, Papadopoulos N, Kinzler KW, Zhou S, Cornish TC, Taube JM, Anders RA, Eshleman JR, Vogelstein B and Diaz LA Jr: PD-1 blockade in tumors with mismatch-repair deficiency. N Engl J Med 372(26): 2509-2520, 2015. PMID: 26028255. DOI: 10.1056/NEJMoa1500596

12 Chalabi M, Fanchi LF, Dijkstra KK, Van den Berg JG, Aalbers AG, Sikorska K, Lopez-Yurda M, Grootscholten C, Beets GL, Snaebjornsson P, Maas M, Mertz M, Veninga V, Bounova G, Broeks A, Beets-Tan RG, de Wijkerslooth TR, van Lent AU, Marsman HA, Nuijten E, Kok NF, Kuiper M, Verbeek WH, Kok M, Van Leerdam ME, Schumacher TN, Voest EE and Haanen JB: Neoadjuvant immunotherapy leads to pathological responses in MMR-proficient and MMR-deficient early-stage colon cancers. Nat Med 26(4): 566-576, 2020. PMID: 32251400. DOI: $10.1038 / \mathrm{s} 41591-020-0805-8$

13 André T, Shiu KK, Kim TW, Jensen BV, Jensen LH, Punt C, Smith D, Garcia-Carbonero R, Benavides M, Gibbs P, de la Fouchardiere C, Rivera F, Elez E, Bendell J, Le DT, Yoshino T, Van Cutsem E, Yang P, Farooqui MZH, Marinello P, Diaz LA Jr and KEYNOTE-177 Investigators: Pembrolizumab in microsatellite-instability-high advanced colorectal cancer. N Engl J Med 383(23): 2207-2218, 2020. PMID: 33264544. DOI: 10.1056/NEJMoa2017699

14 Oliveira AF, Bretes L and Furtado I: Review of PD-1/PD-L1 inhibitors in metastatic dMMR/MSI-H colorectal cancer. Front Oncol 9: 396, 2019. PMID: 31139574. DOI: 10.3389/fonc.2019. 00396

15 Kather JN and Halama N: Harnessing the innate immune system and local immunological microenvironment to treat colorectal cancer. Br J Cancer 120(9): 871-882, 2019. PMID: 30936499. DOI: $10.1038 / \mathrm{s} 41416-019-0441-6$

16 Pernot S, Terme M, Voron T, Colussi O, Marcheteau E, Tartour $\mathrm{E}$ and Taieb J: Colorectal cancer and immunity: what we know 
and perspectives. World J Gastroenterol 20(14): 3738-3750, 2014. PMID: 24833840. DOI: 10.3748/wjg.v20.i14.3738

17 Markman JL and Shiao SL: Impact of the immune system and immunotherapy in colorectal cancer. J Gastrointest Oncol 6(2): 208-223, 2015. PMID: 25830040. DOI: 10.3978/j.issn.20786891.2014 .077

18 Passardi A, Canale M, Valgiusti $M$ and Ulivi P: Immune checkpoints as a target for colorectal cancer treatment. Int J Mol Sci 18(6): 1324, 2017. PMID: 28635639. DOI: 10.3390/ijms 18061324

19 Song $M$ and Chan AT: The potential role of exercise and nutrition in harnessing the immune system to improve colorectal cancer survival. Gastroenterology 155(3): 596-600, 2018. PMID: 30076837. DOI: $10.1053 /$ j.gastro.2018.07.038

20 Guinney J, Dienstmann R, Wang X, de Reyniès A, Schlicker A, Soneson C, Marisa L, Roepman P, Nyamundanda G, Angelino P, Bot BM, Morris JS, Simon IM, Gerster S, Fessler E, De Sousa E Melo F, Missiaglia E, Ramay H, Barras D, Homicsko K, Maru D, Manyam GC, Broom B, Boige V, Perez-Villamil B, Laderas T, Salazar R, Gray JW, Hanahan D, Tabernero J, Bernards R, Friend SH, Laurent-Puig P, Medema JP, Sadanandam A, Wessels L, Delorenzi M, Kopetz S, Vermeulen L and Tejpar S: The consensus molecular subtypes of colorectal cancer. Nat Med 21(11): 13501356, 2015. PMID: 26457759. DOI: 10.1038/nm.3967

21 Dienstmann R, Vermeulen L, Guinney J, Kopetz S, Tejpar S and Tabernero J: Consensus molecular subtypes and the evolution of precision medicine in colorectal cancer. Nat Rev Cancer 17(2): 79-92, 2017. PMID: 28050011. DOI: 10.1038/nrc.2016.126

22 Müller MF, Ibrahim AE and Arends MJ: Molecular pathological classification of colorectal cancer. Virchows Arch 469(2): 125134, 2016. PMID: 27325016. DOI: 10.1007/s00428-016-1956-3

23 Buechler SA, Stephens MT, Hummon AB, Ludwig K, Cannon E, Carter TC, Resnick J, Gökmen-Polar Y and Badve SS: ColoType: a forty gene signature for consensus molecular subtyping of colorectal cancer tumors using whole-genome assay or targeted RNA-sequencing. Sci Rep 10(1): 12123, 2020. PMID: 32694712. DOI: 10.1038/s41598-020-69083-y

24 Martini G, Dienstmann R, Ros J, Baraibar I, Cuadra-Urteaga JL, Salva F, Ciardiello D, Mulet N, Argiles G, Tabernero J and Elez E: Molecular subtypes and the evolution of treatment management in metastatic colorectal cancer. Ther Adv Med Oncol 12: 1758835920936089, 2020. PMID: 32782486. DOI: $10.1177 / 1758835920936089$

25 Vasaikar S, Huang C, Wang X, Petyuk VA, Savage SR, Wen B, Dou Y, Zhang Y, Shi Z, Arshad OA, Gritsenko MA, Zimmerman LJ, McDermott JE, Clauss TR, Moore RJ, Zhao R, Monroe ME, Wang YT, Chambers MC, Slebos RJC, Lau KS, Mo Q, Ding L, Ellis M, Thiagarajan M, Kinsinger CR, Rodriguez H, Smith RD, Rodland KD, Liebler DC, Liu T, Zhang B and Clinical Proteomic Tumor Analysis Consortium: Proteogenomic analysis of human colon cancer reveals new therapeutic opportunities. Cell 177(4): 10351049.e19, 2019. PMID: 31031003. DOI: 10.1016/j.cell.2019.03.030

26 Cancer Genome Atlas Network: Comprehensive molecular characterization of human colon and rectal cancer. Nature 487(7407): 330-337, 2012. PMID: 22810696. DOI: 10.1038/ nature 11252

27 Lech G, Słotwiński R, Słodkowski M and Krasnodębski IW: Colorectal cancer tumour markers and biomarkers: Recent therapeutic advances. World J Gastroenterol 22(5): 1745-1755, 2016. PMID: 26855534. DOI: 10.3748/wjg.v22.i5.1745
28 Storli KE, Søndenaa K, Furnes B and Eide GE: Outcome after introduction of complete mesocolic excision for colon cancer is similar for open and laparoscopic surgical treatments. Dig Surg 30(4-6): 317-327, 2013. PMID: 24022524. DOI: 10.1159/00035 4580

29 Glimelius B, Jakobsen A, Graf W, Berglund A, Gadeberg C, Hansen P, Kjaer M, Brunsgaard N, Sandberg E, Lindberg B, Sellström H, Lorentz T, Påhlman L and Gustavsson B: Bolus injection (2-4 $\mathrm{min}$ ) versus short-term (10-20 $\mathrm{min}$ ) infusion of 5fluorouracil in patients with advanced colorectal cancer: a prospective randomised trial. Nordic Gastrointestinal Tumour Adjuvant Therapy Group. Eur J Cancer 34(5): 674-678, 1998. PMID: 9713273. DOI: 10.1016/s0959-8049(97)10055-7

30 Sørbye H and Dahl O: Nordic 5-fluorouracil/leucovorin bolus schedule combined with oxaliplatin (Nordic FLOX) as first-line treatment of metastatic colorectal cancer. Acta Oncol 42(8): 827831, 2003. PMID: 14968943. DOI: 10.1080/02841860310018972

31 Vethe H, Bjørlykke Y, Ghila LM, Paulo JA, Scholz H, Gygi SP, Chera $\mathrm{S}$ and Ræder $\mathrm{H}$ : Probing the missing mature $\beta$-cell proteomic landscape in differentiating patient iPSC-derived cells. Sci Rep 7(1): 4780, 2017. PMID: 28684784. DOI: 10.1038/ s41598-017-04979-w

32 Paulo JA and Gygi SP: A comprehensive proteomic and phosphoproteomic analysis of yeast deletion mutants of 14-3-3 orthologs and associated effects of rapamycin. Proteomics 15(2-3): 474-486, 2015. PMID: 25315811. DOI: 10.1002/pmic.201400155

33 McAlister GC, Nusinow DP, Jedrychowski MP, Wühr M, Huttlin EL, Erickson BK, Rad R, Haas W and Gygi SP: MultiNotch MS3 enables accurate, sensitive, and multiplexed detection of differential expression across cancer cell line proteomes. Anal Chem 86(14): 7150-7158, 2014. PMID: 24927332. DOI: $10.1021 / \mathrm{ac} 502040 \mathrm{v}$

34 Huttlin EL, Jedrychowski MP, Elias JE, Goswami T, Rad R, Beausoleil SA, Villén J, Haas W, Sowa ME and Gygi SP: A tissue-specific atlas of mouse protein phosphorylation and expression. Cell 143(7): 1174-1189, 2010. PMID: 21183079. DOI: $10.1016 / j . c e l l .2010 .12 .001$

35 Beausoleil SA, Villén J, Gerber SA, Rush J and Gygi SP: A probability-based approach for high-throughput protein phosphorylation analysis and site localization. Nat Biotechnol 24(10): 1285-1292, 2006. PMID: 16964243 . DOI: 10.1038/nbt1240

36 Elias JE and Gygi SP: Target-decoy search strategy for mass spectrometry-based proteomics. Methods Mol Biol 604: 55-71, 2010. PMID: 20013364. DOI: 10.1007/978-1-60761-444-9_5

37 Elias JE and Gygi SP: Target-decoy search strategy for increased confidence in large-scale protein identifications by mass spectrometry. Nat Methods 4(3): 207-214, 2007. PMID: 17327847. DOI: $10.1038 /$ nmeth 1019

38 McAlister GC, Huttlin EL, Haas W, Ting L, Jedrychowski MP, Rogers JC, Kuhn K, Pike I, Grothe RA, Blethrow JD and Gygi SP: Increasing the multiplexing capacity of TMTs using reporter ion isotopologues with isobaric masses. Anal Chem 84(17): 7469-7478, 2012. PMID: 22880955. DOI: 10.1021/ac301572t

39 Tyanova S, Temu T, Sinitcyn P, Carlson A, Hein MY, Geiger T, Mann M and Cox J: The Perseus computational platform for comprehensive analysis of (prote)omics data. Nat Methods 13(9): 731-740, 2016. PMID: 27348712. DOI: 10.1038/nmeth.3901

40 Perez-Riverol Y, Csordas A, Bai J, Bernal-Llinares M, Hewapathirana S, Kundu DJ, Inuganti A, Griss J, Mayer G, Eisenacher M, Pérez E, Uszkoreit J, Pfeuffer J, Sachsenberg T, 
Yilmaz S, Tiwary S, Cox J, Audain E, Walzer M, Jarnuczak AF, Ternent T, Brazma A and Vizcaíno JA: The PRIDE database and related tools and resources in 2019: improving support for quantification data. Nucleic Acids Res 47(D1): D442-D450, 2019. PMID: 30395289. DOI: $10.1093 /$ nar/gky1106

41 Deutsch EW, Bandeira N, Sharma V, Perez-Riverol Y, Carver JJ, Kundu DJ, García-Seisdedos D, Jarnuczak AF, Hewapathirana S, Pullman BS, Wertz J, Sun Z, Kawano S, Okuda S, Watanabe Y, Hermjakob H, MacLean B, MacCoss MJ, Zhu Y, Ishihama Y and Vizcaíno JA: The ProteomeXchange consortium in 2020: enabling 'big data' approaches in proteomics. Nucleic Acids Res 48(D1): D1145-D1152, 2020. PMID: 31686107. DOI: 10.1093/nar/gkz984

42 Lee MS, Menter DG and Kopetz S: Right versus left colon cancer biology: integrating the consensus molecular subtypes. J Natl Compr Canc Netw 15(3): 411-419, 2017. PMID: 28275039. DOI: $10.6004 /$ jncen.2017.0038

43 Yaeger R, Chatila WK, Lipsyc MD, Hechtman JF, Cercek A, Sanchez-Vega F, Jayakumaran G, Middha S, Zehir A, Donoghue MTA, You D, Viale A, Kemeny N, Segal NH, Stadler ZK, Varghese AM, Kundra R, Gao J, Syed A, Hyman DM, Vakiani E, Rosen N, Taylor BS, Ladanyi M, Berger MF, Solit DB, Shia J, Saltz L and Schultz N: Clinical sequencing defines the genomic landscape of metastatic colorectal cancer. Cancer Cell 33(1): 125136.e3, 2018. PMID: 29316426. DOI: 10.1016/j.ccell.2017.12.004

44 Argilés G, Tabernero J, Labianca R, Hochhauser D, Salazar R, Iveson T, Laurent-Puig P, Quirke P, Yoshino T, Taieb J, Martinelli E, Arnold D and ESMO Guidelines Committee: Localised colon cancer: ESMO Clinical Practice Guidelines for diagnosis, treatment and follow-up. Ann Oncol 31(10): 1291-1305, 2020 PMID: 32702383. DOI: 10.1016/j.annonc.2020.06.022

45 Shankaran V, Ikeda H, Bruce AT, White JM, Swanson PE, Old LJ and Schreiber RD: IFNgamma and lymphocytes prevent primary tumour development and shape tumour immunogenicity. Nature 410(6832): 1107-1111, 2001. PMID: 11323675. DOI: $10.1038 / 35074122$
46 Gonzalez H, Hagerling $\mathrm{C}$ and Werb $\mathrm{Z}$ : Roles of the immune system in cancer: from tumor initiation to metastatic progression. Genes Dev 32(19-20): 1267-1284, 2018. PMID: 30275043. DOI: $10.1101 / \mathrm{gad} .314617 .118$

47 Tauriello DVF, Palomo-Ponce S, Stork D, Berenguer-Llergo A, Badia-Ramentol J, Iglesias M, Sevillano M, Ibiza S, Cañellas A, Hernando-Momblona X, Byrom D, Matarin JA, Calon A, Rivas EI, Nebreda AR, Riera A, Attolini CS and Batlle E: TGF $\beta$ drives immune evasion in genetically reconstituted colon cancer metastasis. Nature 554(7693): 538-543, 2018. PMID: 29443964. DOI: 10.1038 /nature25492

48 Wang J, Liu J, Tian F, Zhan Y and Kong D: Cyclin-dependent kinase 9 expression and its association with $\mathrm{CD}^{+} \mathrm{T}$ cell infiltration in microsatellite-stable colorectal cancer. Oncol Lett 18(6): 60466056, 2019. PMID: 31788079. DOI: 10.3892/ol.2019.10970

49 Xiao W, Ibrahim ML, Redd PS, Klement JD, Lu C, Yang D, Savage NM and Liu K: Loss of Fas expression and function is coupled with colon cancer resistance to immune checkpoint inhibitor immunotherapy. Mol Cancer Res 17(2): 420-430, 2019. PMID: 30429213. DOI: 10.1158/1541-7786.MCR-18-0455

50 Klement JD, Paschall AV, Redd PS, Ibrahim ML, Lu C, Yang D, Celis E, Abrams SI, Ozato K and Liu K: An osteopontin/CD44 immune checkpoint controls $\mathrm{CD}^{+} \mathrm{T}$ cell activation and tumor immune evasion. J Clin Invest 128(12): 5549-5560, 2018. PMID: 30395540. DOI: 10.1172/JCI123360
Received December 21, 2021

Revised January 10, 2022

Accepted January 12, 2022 